\title{
OCCURRENCE AND ANTIMICROBIAL RESISTANCE OF Salmonella spp. AND OTHER ENTEROBACTERIA RECOVERED FROM KITCHEN EQUIPMENT OF A UNIVERSITY HOSPITAL IN RIO DE JANEIRO, BRAZIL
}

\section{MIYAHIRA R.F., SANTOS E.F.A.S., FREITAS-ALMEIDA A.C. AND QUEIROZ M.L.P.*}

Dept. de Microbiologia, Imunologia e Parasitologia, Faculdade de Ciências Médicas, Universidade do Estado do Rio de Janeiro -UERJ- Brasil. *Corresponding Author: Email- qmara6@gmail.com

Received: August 12, 2013; Accepted: September 07, 2013

\begin{abstract}
-
Introduction: One of the most significant risk factors identified in food contamination is cross-contamination among the food and the preparation surfaces. We verified the occurrence and the antimicrobial resistance of enterobacteria in equipment used to prepare diets to hospitalized patients in a university hospital in Rio de Janeiro, Brazil.

Methods: A total of 60 samples were collected from semi-industrial equipment (one blender and one mixer) in the hospital's kitchen. Enterobacteriaceae species were identified by classical methods. Antimicrobial susceptibility testing was carried out by the disk diffusion method and minimum inhibitory concentration was determined by the broth microdilution method. The detection of beta-lactamases genes was determined by PCR.

Results: Ninety-seven isolates of Enterobacteriaceae have been identified. We isolated six Salmonella spp. The susceptibility test revealed that $77 \%(n=75)$ of the isolates presented resistance to at least one antimicrobial agent. The search for extended-spectrum beta-lactamases genes indicated the presence of blasHv gene in a Klebsiella pneumoniae subsp. pneumoniae isolate. The sequencing identified the SHV-36 enzyme.

Conclusion: We found important enterobacteria contamination in the hospital kitchen equipment, indicating that the hygiene procedures should be improved. Furthermore, we recovered Salmonella spp. isolates from both the blender and the mixer, showing that diets may act as potential vehicles for the dissemination of enteropathogens in this scenario.
\end{abstract}

Keywords- Hospital diets, Salmonella spp., Enterobacteria, Kitchen equipment, Antimicrobial resistance, beta-lactamases

Citation: Miyahira R.F., et al. (2013) Occurrence and Antimicrobial Resistance of Salmonella spp. and Other Enterobacteria Recovered from Kitchen Equipment of a University Hospital in Rio de Janeiro, Brazil. International Journal of Microbiology Research, ISSN: 0975-5276 \& EISSN: 0975-9174, Volume 5, Issue 5, pp.-467-471.

Copyright: Copyright@2013 Miyahira R.F., et al. This is an open-access article distributed under the terms of the Creative Commons Attribution License, which permits unrestricted use, distribution and reproduction in any medium, provided the original author and source are credited.

\section{Introduction}

Foodborne diseases, particularly gastrointestinal infections, represent a very large group of pathologies with strong negative impact in public health because of their widespread nature. Little consideration is given to those infections due to the fact that their symptoms are often moderate and self-limiting. However, food contamination can be very dangerous if occurring in a hospitalized patient. Food hygiene in hospital poses peculiar problems, mainly by the presence of patients who may be more vulnerable to microbiological and nutritional risks than healthy subjects [1].

One of the most significant risk factors identified in food contamination is cross-contamination among the food and the preparation surfaces. The failure to effectively remove bacteria from food contact surfaces may have serious implications in the transmission of foodborne diseases [2]. The risk of cross-contamination is further increased if the food temperature is not subsequently controlled or a surface is left uncleaned, permitting bacterial growth [3]. Various bacteria, including Escherichia coli and Salmonella spp. survive on hands, sponges, utensils and currency for hours or days. Therefore, the relationship between contaminated surfaces and transmission of foodborne pathogens is evident in food processing [4].

Members of the Enterobacteriaceae family are important causes of healthcare-associated infection. Emerging resistance in Enterobacteriaceae is a significant problem that requires immediate attention [5]. Antimicrobial resistance is an increasing threat in hospitalized patients and both mortality and morbidity from infection are higher when caused by antimicrobial-resistant bacteria. The growing prevalence of multiresistant pathogens in nosocomial settings is frequently related to the high selective pressure of antimicrobials commonly used in hospitalized patients [6].

The most common mechanism of resistance among Enterobacteriaceae is the production of extended-spectrum beta-lactamases (ESBL), which can inactivate certain beta-lactam antibiotics [7]. Therefore, most ESBL producers often exhibit multidrug-resistance phenotypes [8]. Considering the high number of immunocompromised patients and the extensive use of antimicrobial agents inside 
hospitals, the study of antibiotic resistance in this environment is very important. Therefore, the aims of this work were to verify the occurrence and antimicrobial resistance of enterobacteria recovered from equipment used to prepare diets to hospitalized patients in a university hospital in the city of Rio de Janeiro, Brazil.

\section{Materials and Methods}

\section{Samples Analysis}

During a 15-week period, a total of 60 samples were collected from semi-industrial equipment (one blender and one mixer) from the kitchen of a tertiary care teaching hospital with 525 beds located in the city of Rio de Janeiro. The choice of the blender and the mixer was made based on the frequency of use and the level of sanitization. The samples were collected from the equipment surfaces after the sanitization processes with sterile swabs twice a week. The swabs were transported in sterile saline solution $(0.85 \% \mathrm{NaCl})$ under refrigeration and immediately processed in the laboratory. The quantitative microbiological analysis of the equipment was performed by two different methods: (1) aerobic colony counts at $35^{\circ} \mathrm{C}$ and (2) determination of most probable number (MPN) of coliform bacteria at $35^{\circ} \mathrm{C}$ and $45^{\circ} \mathrm{C}$, according to the recommendations of the American Public Health Association (APHA) [9]. After the determination of MPN of coliforms, the presence of Enterobacteriaceae was evaluated by plating $0.1 \mathrm{~mL}$ of the growth in EC broth onto Eosin Methyl Blue Agar (EMB, OXOID, LTD., Basingstoke, Hampshire, England). The characteristic colonies were stored in glycerol GC $20 \%$ at $-20^{\circ} \mathrm{C}$.

\section{Physiological Characterization of Enterobacteriaceae}

After storage, strains were inoculated into $3 \mathrm{~mL}$ of Brain Heart Infusion (BHI, Difco, Becton Dickinson, Maryland, USA) and incubated at $35 \pm 2^{\circ} \mathrm{C}$ for $24 \mathrm{hrs}$. Growth was plated on EMB agar plates and incubated at $35 \pm 2^{\circ} \mathrm{C}$ for $24 \mathrm{hrs}$. Up to five different colony types from each sample were identified by classical methodology as a species of the Enterobacteriaceae family $[10,11]$.

\section{Antimicrobial Susceptibility Testing and Screening of $\beta$ - lactamases}

Isolates were tested by the disk diffusion method, according to the recommendations of the Clinical and Laboratory Standards Institute (CLSI) [12]. The following antimicrobial drugs were tested (OXOID): cefepime $(30 \mu \mathrm{g})$, aztreonam $(30 \mu \mathrm{g})$, chloramphenicol $(30 \mu \mathrm{g})$, cephalotin $(30 \mu \mathrm{g})$, cefoxitin $(30 \mu \mathrm{g})$, imipenem $(10 \mu \mathrm{g})$, tetracycline $(30 \mu \mathrm{g})$, gentamicin $(10 \mu \mathrm{g})$, cefotaxime $(30 \mu \mathrm{g})$, amikacin $(30 \mu \mathrm{g})$, sulfamethoxazole/trimethoprim $(1.25 \mu \mathrm{g} / 23.75 \mu \mathrm{g})$, ceftazidime (30 $\mu \mathrm{g})$, ampicillin $(10 \mu \mathrm{g})$, tobramycin $(10 \mu \mathrm{g})$, ciprofloxacin $(5 \mu \mathrm{g})$, ampicillin/sulbactam $(10 \mu \mathrm{g} / 10 \mu \mathrm{g})$ and nalidixic acid $(30 \mu \mathrm{g})$ (Salmonella spp.). Disk diffusion assays with ceftazidime $(30 \mu \mathrm{g})$, ceftazidime+clavulanic acid $(10 / 10 \mu \mathrm{g})$, cefotaxime $(30 \mu \mathrm{g})$ and cefotaxime+clavulanic acid $(30 / 10 \mu \mathrm{g})$ were performed for the detection of ESBL among strains showing positive results on the initial screening test for ESBL recommended by the CLSI [12]. For the detection of AmpC beta-lactamases, the approximation disk test with cefoxitin $(30 \mu \mathrm{g})$ and cefotaxime $(30 \mu \mathrm{g})$ was used [13]. Reference strains E. coli ATCC 25922, E. coli ATCC 35218 and Klebsiella pneumoniae ATCC 700603 were used as control.

\section{Minimum Inhibitory Concentration (MIC)}

Isolates with positive results on the screening tests for ESBL and AmpC beta-lactamases had their MICs determined for ceftazidime/ cefotaxime and cefoxitin, respectively. MIC was determined by the broth microdilution method using cation-adjusted Mueller-Hinton broth (Difco Laboratories), according to CLSI guidelines [12]. Reference strain E. coli ATCC 25922 was used as control.

\section{Detection of Beta-lactamase Genes}

The detection of beta-lactamase genes was determined by Polymerase Chain Reaction (PCR). Specific primers were used for the detection of the blatem, blasнv, blaoxA-1, blactx-m and blacmy-2 genes [14]. DNA was extracted by thermal lysis. The PCR was performed in a $50 \mu \mathrm{L}$ reaction mixture containing: $31 \mu \mathrm{L}$ of ultra pure water, $1 \mathrm{x}$ Taq polymerase buffer, $1.5 \mathrm{mM} \mathrm{MgCl}_{2}, 20 \mu \mathrm{M}$ of each primer, $2 \mathrm{mM}$ of each dNTP, $0.5 \cup$ Taq DNA polimerase (Invitrogen, Carlsbad, California, USA) and $5 \mu \mathrm{L}$ of DNA template. Positive control strains were kindly provided by the Enterobacteria Laboratory of the Oswaldo Cruz Institute (Rio de Janeiro, Brazil). E. coli DH5-a was used as negative control for all reactions. PCR products were separated by electrophoresis in $1 \%$ agarose gels $(1 \times$ TBE) at $100 \mathrm{~V}$, stained with ethidium bromide and photographed under UV light.

\section{Sequencing of $\beta$-lactamase Genes}

Before sequencing, all PCR products were purified using the AxyPrep Bacterial Genomic DNA Miniprep Kit (Axygen Biosciences). Sequencing reactions were performed with the same primers used for PCR detection using the DYEnamic ET terminator cycle sequencing kit (GE Healthcare). Chromatograms were transformed into FASTA format with Phred software [15]. The obtained nucleotide sequences were analysed by BLAST [16] searches in GenBank database (http://www.ncbi.nlm.nih.gov) and were aligned with representative bacterial sequences obtained from the public databases using ClustalX software [17].

\section{Results}

The Brazilian legislation does not establish microbiological standards to swab tests in kitchen equipment. Dancer suggests that microbial counts on food-processing equipment should be $<5 \mathrm{CFU} /$ $\mathrm{cm}^{2}$ [18]. We found colony counts above $2 \times 10 \mathrm{CFU} / \mathrm{cm}^{2}$ in $70 \%$ of the equipment. Coliform counts higher than $10 \mathrm{MPN} \mathrm{mL}-1$ at $35^{\circ} \mathrm{C}$ were observed in the blender (76.6\%) and the mixer (73.3\%). Similarly, the percentage of samples presenting coliform contamination at $45^{\circ} \mathrm{C}$ was $66.6 \%$ (blender) and $63.3 \%$ (mixer). The physiological characterization indicated 97 Enterobacteriaceae isolates: 58 from the mixer and 39 from the blender [Table-1]. Enterobacter spp. was the most frequent isolate $(37 \% ; n=36 / 97)$, followed by Klebsiella spp. $(19 \% ; n=18 / 97)$ and Citrobacter spp. $(19 \% ; n=18 / 97)$. We isolated six Salmonella spp. (6\%), four from the mixer and two from the blender.

The susceptibility test revealed that $77 \%(n=75)$ of the isolates showed resistance to at least one antimicrobial agent tested and $38 \%(n=37)$ presented multiple resistance (three or more drugs). Resistance or intermediate resistance to seven antimicrobial agents was observed in two isolates of Enterobacter cloacae. We found 12 isolates with ceftazidime, cefotaxime or aztreonam inhibition zone diameters compatible with the initial screening test for ESBL recommended by the CLSI [12]. From these 12 isolates, seven were isolated from the blender and five from the mixer. Ten of these isolates presented multiple antimicrobial resistance, while eight were resistant to cefotaxime and four to ceftazidime. The expression of AmpC beta-lactamases was observed in 32 isolates; however, 31 were identified as belonging to the ECSM species (Enterobacter spp., Citrobacter spp., Serratia spp., and Morganella morganii), with known chromosomally encoded AmpC beta-lactamases. One of the 
isolates showing this phenotype was characterized as $K$. pneumoniae subsp. pneumoniae. Three Salmonella spp. isolates were resistant to nalidixic acid and susceptible to ciprofloxacin.

\section{Table 1- Enterobacteriaceae isolates recovered from a mixer and a} blender used to prepare diets for hospitalized patients

\begin{tabular}{|c|c|c|c|c|}
\hline \multirow{2}{*}{ Genus } & \multirow{2}{*}{ Species or Serotypes } & \multicolumn{2}{|c|}{ Equipment } & \multirow{2}{*}{ Tota } \\
\hline & & Mixer & Blender & \\
\hline \multirow{3}{*}{ Citrobacter } & C. braakii & 2 & 1 & \multirow{3}{*}{18} \\
\hline & C. gillenii & 9 & 5 & \\
\hline & C. murliniae & 0 & 1 & \\
\hline \multirow{7}{*}{ Enterobacter } & E. aerogenes & 4 & 0 & \multirow{7}{*}{36} \\
\hline & E. amnigenus Biogroup 1 & 4 & 4 & \\
\hline & E. asburiae & 1 & 0 & \\
\hline & E. cloacae & 7 & 5 & \\
\hline & E. cowanii & 2 & 0 & \\
\hline & E. intermedium & 1 & 2 & \\
\hline & E. kobei & 5 & 1 & \\
\hline Escherichia & E. coli & 4 & 2 & 6 \\
\hline \multirow{2}{*}{ Klebsiella } & K. pneumoniae subsp. ozaenae & 2 & 0 & \multirow{2}{*}{18} \\
\hline & K. pneumoniae subsp. pneumoniae & 7 & 9 & \\
\hline Pantoea & P. agglomerans & 0 & 2 & 2 \\
\hline \multirow{2}{*}{ Raoultuella } & R. planticola & 1 & 0 & \multirow{2}{*}{11} \\
\hline & R. terrigena & 5 & 5 & \\
\hline \multirow{3}{*}{ Salmonella } & S. Give & 2 & 0 & \multirow{3}{*}{6} \\
\hline & S. Enteritidis & 1 & 1 & \\
\hline & S. Typhimurium & 1 & 1 & \\
\hline Total & & 58 & 39 & 97 \\
\hline
\end{tabular}

MIC results indicated that all AmpC beta-lactamase producing isolates were resistant to cefoxitin (MIC $\geq 32 \mu \mathrm{g} / \mathrm{mL}$ ). However, the blacmy-2 gene was not found in these isolates. From the 12 isolates with ceftazidime, cefotaxime or aztreonam inhibition zone diameters compatible with the initial screening test for ESBL, 11 were found to be resistant or intermediate resistant to cefotaxime (MIC > $1 \mu \mathrm{g} / \mathrm{mL}$ ) and three were found to be resistant or intermediate resistant to ceftazidime (MIC $>4 \mu \mathrm{g} / \mathrm{mL}$ ) [Table-2]. The search for ESBL genes in these 12 Enterobacteriaceae isolates indicated the presence of the blasнv gene in a $K$. pneumoniae subsp. pneumoniae isolate recovered from the blender [Fig-1]. Sequence results identified as the SHV-36 enzyme.

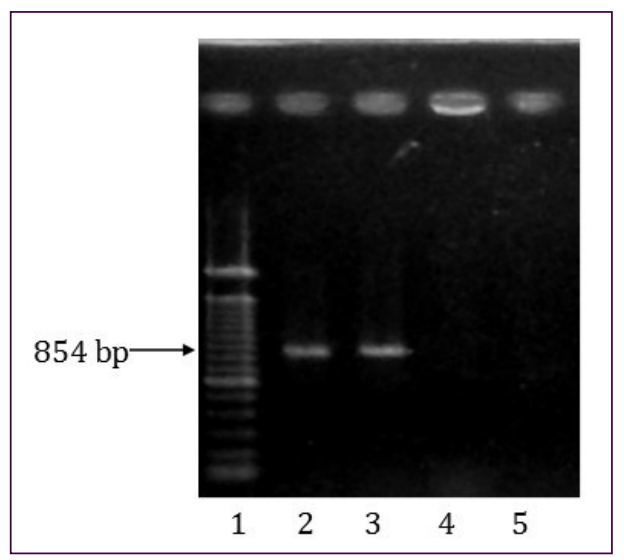

Fig. 1- PCR amplification of blastv gene. Lane 1: 100bp ladder; lane 2: E. coli 18 (positive control); lane 3: Klebsiella pneumoniae subsp. pneumoniae K42; lane 4: E. coli DH5-a (negative control) and lane 5: reaction mix.

Table 2- Minimum Inhibitory Concentration (MIC) values, antimicrobial susceptibility and presence of beta-lactamase genes in isolates with inhibition zone diameters compatible with the initial screening test for ESBL.

\begin{tabular}{|c|c|c|c|c|c|c|c|}
\hline \multirow{2}{*}{ Isolate } & \multirow{2}{*}{ Origin } & \multirow{2}{*}{ Species } & \multicolumn{2}{|r|}{ Ceftazidime } & \multicolumn{2}{|r|}{ Cefotaxime } & \multirow{2}{*}{$\begin{array}{c}\text { Presence of } \\
\beta \text {-lactamase genes }\end{array}$} \\
\hline & & & $\operatorname{MIC}(\mu \mathrm{g} / \mathrm{mL})$ & Antimicrobial susceptibility (mm) & $\operatorname{MIC}(\mu \mathrm{g} / \mathrm{mL})$ & Antimicrobial susceptibility (mm) & \\
\hline E100 & blender & Enterobacter cloacae & $<0.5$ & 26 & 64 & 6 & none \\
\hline EC99 & mixer & Escherichia coli & $<0.5$ & 25 & 2 & 26 & none \\
\hline $\mathrm{C} 90$ & blender & Citrobacter gillenii & $<0.5$ & 27 & 8 & 28 & none \\
\hline S84 & mixer & Salmonella Give & $<0.5$ & 24 & 8 & 27 & none \\
\hline$S 79 b$ & mixer & Salmonella Typhimurium & $<0.5$ & 21 & 8 & 21 & none \\
\hline S76b & mixer & Salmonella Give & $<0.5$ & 6 & 4 & 10 & none \\
\hline E66 & mixer & Enterobacter cloacae & 16 & 6 & $>128$ & 6 & none \\
\hline K42 & blender & K. pneumoniae subsp. pneumoniae & $<0.5$ & 26 & 1 & 26 & blasHV \\
\hline E29 & blender & Enterobacter cloacae & 16 & 6 & 16 & 6 & none \\
\hline E27 & blender & Enterobacter kobei & 8 & 8 & $>128$ & 12 & none \\
\hline E26 & blender & Enterobacter cloacae & 1 & 20 & 2 & 10 & none \\
\hline K6a & mixer & K. pneumoniae subsp. ozaenae & 4 & 25 & 4 & 6 & none \\
\hline
\end{tabular}

\section{Discussion}

The importance of microbial surface contamination for the epidemiology of infectious diseases has long been recognized. Environmental surface contamination has also been specifically implicated in a number of hospital-acquired infections. The potential for contaminated surfaces to contribute to the transmission of pathogens depends on several factors, including the ability of pathogens to remain viable on different environmental surfaces, the frequency with which they contaminate surfaces and whether the levels of contamination are high enough to result in transmission to patients $[19,20]$.
Nevertheless, few studies have evaluated the contamination of surfaces in hospital kitchens. We found colony counts above $2 \times 10$ CFU / mL in $70 \%$ of the samples analyzed. A study developed in two hospitals in Egypt examined the contamination of utensils used in the preparation of diets. The authors performed aerobic mesophilic counts by swabbing the surfaces of the following food utensils: meat knives, vegetable knives, meat chopping boards, salad chopping boards, cooking pan, roasting pan, patient tray and food distribution containers. Similarly to our results, the authors found aerobic mesophilic counts exceeding $10^{2} \mathrm{CFU} / \mathrm{mL}$ in all food utensils, except the food distribution containers. They also highlighted 
that the contaminated surfaces of equipment and utensils in a hospital kitchen may be vehicles of infection and may also promote the spread of pathogens in the nosocomial environment [21].

Healthcare-associated infections are increasing in prevalence due to a number of factors, including aging populations, increasing number of immunocompromised patients, as well as increasing use of invasive interventions [22]. During the last few decades, the frequency and the spectrum of antibiotic resistant infections have increased steadily within the United States, Europe and the developing world. This increase has been attributed to a combination of microbial characteristics, the selective pressure of antimicrobial use, and social and technical changes [23]

Our results indicated the presence of many multiresistant Enterobacteriaceae in the hospital kitchen equipment. Therefore, the diets prepared in the blender and the mixer may potentially disseminate isolates with important resistance profiles inside the hospital, especially because the food does not suffer heat treatment after the use of the equipment. Disk diffusion tests indicated higher rates of antimicrobial resistance in Enterobacter spp., Citrobacter spp., Raoultella spp, Klebsiella spp. and Salmonella spp. isolates.

Enterobacter cloacae was one of the 10 most common blood culture pathogens identified in Canadian hospitals between 2007 and 2009 [24]. ESBL-producing E. cloacae are being increasingly reported worldwide. In a study conducted at a hospital in Tunis, of the 66 E. cloacae isolates tested, $44(67 \%)$ were ESBL producers [25]. In our investigation, Enterobacter spp. was the most frequent microorganism (37\%) and two E. cloacae isolates presented resistance or intermediate resistance to seven antimicrobial agents.

K. pneumoniae, one of the most important nosocomial pathogens, has demonstrated the ability to develop and/or acquire new resistance determinants and is thought to be a reservoir of antimicrobial resistance genes [26]. In our research, we detected the blasHv${ }_{36}$ gene in a K. pneumoniae subsp. pneumoniae isolate recovered from the blender. However, according to the classification of betalactamases (www.lahey.org/studies), it is still not clear whether the SHV-36 is an ESBL.

Conversely, Munday et al. classified the SHV-36 beta-lactamase as an ESBL [27]. They identified the blasHV-36 gene in a Klebsiella spp. isolate recovered from faeces submitted for the diagnosis of diarrheal disease from a hospital-based patient in York, United Kingdom. The MIC results showed resistance to cefotaxime (MIC $=4$ $\mathrm{mg} / \mathrm{L}$ ) and susceptibility to ceftazidime (MIC $<0.25 \mathrm{mg} / \mathrm{L}$ ) [27]. Our results indicated that the $K$. pneumoniae isolate was susceptible to both antimicrobials (ceftazidime $=1 \mu \mathrm{g} / \mathrm{mL}$ and cefotaxime $=2 \mu \mathrm{g} /$ $\mathrm{mL}$ ). A study conducted in Portugal also detected the blasHv-36 gene in K. pneumoniae clinical isolates and considered this enzyme as a broad-spectrum beta-lactamase [28].

The $K$. pneumoniae isolate also showed a presumptive AmpCproducing phenotype. However, we could not find the blacmy-2 gene. Many nosocomial isolates of Klebsiella spp. producing plasmidmediated AmpC $\beta$-lactamases have been involved in several worldwide outbreaks of infection. Often, genes encoding plasmidmediated AmpC beta-lactamases coexist in the same plasmid with genes encoding mechanisms of resistance to other classes of antibiotics, leaving clinicians with limited therapeutic options [29].

Of the twelve Enterobacteriaceae strains with positive results on the initial screening test for ESBL, eleven were resistant to cefotaxime and three to ceftazidime. These findings are of great concern, since these drugs are widely used in hospitals. Although the betalactamase encoding genes have not been found in these strains, we believe that the observed phenotype is probably related to the presence of other genes that have not been investigated and/or the primers used in this study [14].

Over the last decade, the high incidence of multidrug resistance in Enterobacteriaceae has become a serious public health problem worldwide. Because of their critical importance for human and veterinary medicine, resistance to extended spectrum beta-lactams, especially third- and fourth-generation cephalosporins and penems, is of special interest. The increasing presence of these betalactamases in pathogenic bacteria limits the therapeutic use of these drugs [8]. They are spread among bacterial species by plasmids, often carrying multiple antibiotic resistance genes [30]. In a prospective study of 455 consecutive episodes of $K$. pneumoniae bacteremia in 12 hospitals in seven countries, 85 episodes were attributed to an ESBL-producing organism. Failure to use an antibiotic active against ESBL-producing $K$. pneumoniae was associated with extremely high mortality [26].

\section{Conclusion}

We found significant contamination in the kitchen equipment used to prepare diets to hospitalized patients. Our findings showed that the safety hygiene procedures in handling the hospital kitchen equipment should be improved. Importantly, reports of our results were sent to the Division of Nutrition of the University Hospital and measures to control the cleaning processes of kitchen equipment were reviewed. Moreover, trainings were offered for food handlers, with the aim of preventing cross-contamination in kitchen environments. Considering that we recovered Salmonella spp. isolates from both the blender and the mixer, our results indicate that diets may act as potential vehicles for the dissemination not only of enteropathogens and enterobacteria, but also of resistance genes.

\section{List of Abbreviations}

APHA: American Public Health Association

ATCC: American Type Culture Collection

BHI: Brain Heart Infusion

CFU: Colony-Forming Unit

CLSI: Clinical and Laboratory Standards Institute

ECSM: Enterobacter spp., Citrobacter spp., Serratia spp. and Morganella morganii

EMB: Eosin Methylene Blue Agar

ESBL: Extended-spectrum beta-lactamases

MIC: Minimum Inhibitory Concentration

MPN: Most Probable Number

PCR: Polymerase Chain Reaction

\section{Acknowledgements}

The present work was supported by funds of Fundação de Amparo à Pesquisa do Estado do Rio de Janeiro (FAPERJ) and Coordenação de Aperfeiçoamento de Pessoal de Nível Superior (CAPES). We would like to thank the Division of Nutrition of the Pedro Ernesto University Hospital for giving us permission to collect material for the study. We would also like to thank Dr. Rodolpho M. Albano and Ms. Denise Oliveira for performing the gene sequencing.

\section{Conflict of Interest : None declared.}




\section{References}

[1] Buccheri C., Casuccio A., Giammanco S., Giammanco M., La Guardia M., Mammina C. (2007) BMC Health Serv. Res., 7, 45.

[2] DeVere E. and Purchase D. (2007) Food Microbiol., 24, 425430.

[3] Tebbutt G., Bell V., Aislabie J. (2007) J. Appl. Microbiol., 102, 1010-1017.

[4] Hasegawa A., Hara-Kudo Y., Kumagai S. (2011) J. Vet. Med. Sci., 73, 1163-1168.

[5] Pitout J.D.D. and Laupland K.B. (2008) Lancet Infect. Dis., 8, 159-166

[6] Slama T.G. (2008) Critical Care, 12, 1-7.

[7] Bush K. and Jacoby G.A. (2010) Antimicrob. Agents Chemother., 54, 969-976.

[8] Pitout J.D.D. (2010) Drugs, 70, 313-333.

[9] APHA (2001) Compendium of Methods for the Microbiological Examination of Foods, 4th ed., 676.

[10]Abbott S.L. (2011) Manual of Clinical Microbiology, 10th ed., 639-657.

[11]Nataro J.P., Bopp C.A., Fields P.I., Kaper J.B., Strockbine N.A. (2011) Manual of Clinical Microbiology, 10th ed., 603-626.

[12]Clinical and Laboratory Standards Institute (2010) Performance Standards for Antimicrobial Susceptibility Testing, 20th Informational Supplement.

[13]Jacoby G.A. (2009) Clin. Microbiol. Rev., 22, 161-182.

[14]Hasman H., Mevius D., Veldman K., Olesen I., Aarestrup F.M. (2005) J. Antimicrob. Chemother., 56, 115-121.

[15]Edwing B., Hillier L., Wendl M., Green P. (1998) Genome Res., 8, 175-185.

[16]Altschul S.F., Gish W., Miller W., Myers E.W., Lipman D.J. (1990) J. Mol. Biol., 5, 403-410.

[17]Thompson J.D., Gibson T.J., Plewniak F., Jeanmougin F., Higgins D.G. (1997) Nucleic Acids Res., 24, 4876-4882.

[18]Dancer S.J. (2004) J. Hosp. Infect., 56, 10-15.

[19]Boyce J.M. (2007) J. Hosp. Infect., 65 (2), 50-54.

[20]Konecka-Matyjek E., MaćKiw E., Krygier B., Tomczuk K., Stoś K., Jarosz M. (2012) Ann. Agric. Environ. Med., 19, 457-463.

[21]El Derea H., Salem E., Fawzi M., Azeem M.A. (2008) East Mediterr Health J., 14, 941-952.

[22]Wu C.J., Lee H.C., Lee N.Y., Shih H.I., Ko N.Y., Wang L.R., Ko W.C. (2003) J. Microbiol. Immunol. Infect., 39, 135-143.

[23]Dzidic S. and Bedeković V. (2003) Acta Pharmaco Sin., 24, 519 $-526$.

[24]Adam H.J., DeCorby M., Rennie R., Karlowsky J.A., Hoban D.J., Zhanel G.G. (2011) Diagn. Microbiol. Infect. Dis., 69, 307313.

[25]Hammami S., Boubaker I.B., Saidani M., Lakhal E., Ben Hassen A., Kamoun A., Ghozzi R., Slim A., Ben Redjeb S. (2012) Microb. Drug Resist., 18, 59-65.

[26]Paterson D.L., Ko W.C., Von Gottberg A., Mohapatra S., Casellas J.M., Goossens H., Mulazimoglu L., Trenholme G., Klugman K.P., Bonomo R.A., Rice L.B., Wagener M.M., McCormack J.G., Yu V.L. (2004) Clin. Infect. Dis., 39, 31-37.
[27]Munday C.J., Whitehead G.M., Todd N.J., Campbell M., Hawkey P.M. (2004) J. Antimicrob. Chemother., 54, 628-633.

[28]Machado E., Coque T.M., Cantón R., Novais A., Sousa J.C., Baquero F., Peixe L. (2007) J. Antimicrob. Chemother., 60, 1370-1374.

[29]Black J.A., Thomson K.S., Buynak J.D., Pitout J.D. (2005) J. Clin. Microbiol., 43, 4168-4171.

[30]Warren R.E., Ensor V.M., O'Neill P., Butler V., Taylor J., Nye K., Harvey M., Livermore D.M., Woodford N., Hawkey P.M. (2008) J. Antimicrob. Chemother., 61, 504-508. 